\title{
Comorbidities Associated with Psoriatic Arthritis Compared with Non-psoriatic Spondyloarthritis: A Cross-sectional Study
}

\author{
Naba Haque, Rik J. Lories, and Kurt de Vlam
}

ABSTRACT. Objective. Psoriatic arthritis (PsA) is a chronic inflammatory skeletal disease associated with health concerns such as obesity, Type II diabetes, dyslipidemia, hypertension (HTN), and cardiovascular (CV) disease. The involvement of these metabolic factors in the pathogenesis, severity, and progression of PsA remains unclear. In our study, we compared comorbidities associated with PsA to those patients with related but non-PsA forms of spondyloarthritis (SpA).

Methods. The SpA database at the Rheumatology Department of University Hospitals Leuven was analyzed in a cross-sectional manner using the demographic, medical, and laboratory information of 518 patients with PsA and non-PsA SpA. The patients were grouped by their diagnosis and evaluated on the basis of sex, age, education, work status, disease duration, treatment, and type and number of comorbidities. The data were assessed using the chi-square test, Student t test, Fisher's exact test, and logistic regression, including correction for multiple testing.

Results. Out of the 518 patients (62.74\% men, 37.25\% women), 53.66\% had comorbidities. The PsA group had 262 patients (mean age $58.8 \mathrm{yrs}$ ) and the non-PsA SpA group had 256 patients (mean age 44.9 yrs, $\mathrm{p}<0.001$ ). The PsA group was found to have more and multiple comorbidities compared with non-PsA SpA $(\mathrm{p}<0.001)$. The CV and metabolic comorbidities were also significantly higher in the PsA group $(\mathrm{p}<0.001)$. Coronary artery disease, HTN, hyperlipidemia, and metabolic syndrome showed a marked difference between the 2 groups $(\mathrm{p}<0.05)$. An increased incidence of malignancy was found in PsA group ( $\mathrm{p}<0.05)$.

Conclusion. Comorbidities and malignancies are increased in patients with PsA compared with nonPsA SpA, irrespective of demographic factors and type of treatment. (First Release December 15 2015; J Rheumatol 2016;43:376-82; doi:10.3899/jrheum.141359)

Key Indexing Terms:

PSORIATIC ARTHRITIS

SPONDYLOARTHRITIS
ANKYLOSING SPONDYLITIS COMORBIDITIES
The psoriatic disease concept includes psoriasis $(\mathrm{PsO})$ and psoriatic arthritis (PsA) ${ }^{1}$. PsO is a chronic relapsing inflammatory skin disease characterized by the presence of scaling lesions, typically localized on the extensor surfaces and the trunk $^{2}$. PsA is a chronic inflammatory skeletal disease associated with $\mathrm{PsO}^{3,4}$. PsA has heterogeneous clinical

From the Department of Development and Regeneration, Skeletal Biology and Engineering Research Center, University of Leuven; Division of Rheumatology, University Hospitals Leuven, Leuven, Belgium.

Supported by the unrestricted Abbvie Chair for psoriatic arthritis research (R. Lories and K. de Vlam).

N. Haque, MD, MS, PhD Student, Division of Rheumatology, University Hospitals Leuven; R.J. Lories, MD, PhD, Professor, Department of Development and Regeneration, Skeletal Biology and Engineering Research Center, University of Leuven, and Division of Rheumatology, University Hospitals Leuven; K. de Vlam, MD, PhD, Consultant, Department of Development and Regeneration, Skeletal Biology and Engineering Research Center, University of Leuven, and Division of Rheumatology, University Hospitals Leuven.

Address correspondence to Dr. K. de Vlam, Division of Rheumatology, UZ Leuven, Herestraat 49, B3000 Leuven, Belgium.

E-mail:Kurt.devlam@uz.kuleuven.be

Accepted for publication October 1, 2015. manifestations with some forms clearly linked to the spondyloarthritis (SpA) concept. A strong relationship of PsA with SpA is clearly supported by shared clinical, genetic, and radiographic characteristics, although the question of whether all subtypes of PsA and in particular the polyarticular and severely joint destructive forms should be considered as SpA is still being debated ${ }^{5}$. The SpA concept itself groups different diagnostic entities and also includes axial SpA [ankylosing spondylitis (AS) and nonradiographic forms], reactive arthritis, arthritis associated with inflammatory bowel disease (IBD), and juvenile and undifferentiated $\mathrm{SpA}^{6}$.

The prevalence of psoriatic disease varies geographically. In white populations, $\mathrm{PsO}$ is frequent $(1-5 \%$ of the population $)^{7}$. Although the prevalence of PsA around the globe is suggested to be around $0.02-0.25 \%$, the prevalence among the patients with $\mathrm{PsO}$ varies between $6 \%$ and $48 \%$, depending on the specific setting of the investigation ${ }^{4,8}$. Over the last decade, therapeutic options for both skin and joint disease have dramatically improved, thereby allowing efficient control of the primary disease manifestations in a majority of patients. The recent therapeutic progress has

Personal non-commercial use only. The Journal of Rheumatology Copyright @ $\odot$ 2016. All rights reserved 
triggered increasing interest in a holistic approach toward psoriatic disease, with specific attention toward detection and treatment of the comorbidities seen in these patients with chronic disease $\mathrm{e}^{9,10,11}$. Comorbidities with a direct effect on mortality or morbidity may include malignancy and metabolic and cardiovascular diseases (CVD), as well as depression ${ }^{11,12,13,14}$.

CV comorbidities are critically important in this patient population because they may directly contribute to an increased mortality seen in patients with PsO and PsA ${ }^{12,13,14}$. An increased prevalence of risk factors for $\mathrm{CV}$ and metabolic diseases has been extensively reported in patients with PsA and $\mathrm{PsO}$, and includes the presence of hypertension (HTN), hyperglycemia, obesity, hyperlipidemia, depression, and metabolic syndrome ${ }^{15-25}$. The latter concept describes the presence of abdominal obesity, atherogenic dyslipidemia, HTN, insulin resistance, proinflammatory state, and prothrombotic state ${ }^{26}$. Disease severity might be involved in the development of such comorbidities as shown in the National Psoriasis Foundation Surveys 2001-2003, in which patients with severe skin disease were at an increased risk of PsA, diabetes, and CVD compared with those having mild to moderate $\mathrm{PsO}^{21}$. However, metabolic syndrome was equally associated with both mild and severe cases in PsO, with only a minor effect of the disease duration and therefore the longterm effect of mild disease may be underestimated ${ }^{22,23}$. Similarly, the CV comorbidities were found to be equally prevalent in early and established PsA with no influence of disease duration ${ }^{27}$. Severe PsO as well as severe PsA could thus be considered independent $\mathrm{CV}$ risk factors ${ }^{28,29}$.

While an increased incidence of non-melanoma skin cancer and other types of cancers including lung cancer has also been reported by a few studies in patients with $\mathrm{PsO}^{30,31}$, another study showed no difference in the risk of malignancy between patients with PsA and a control population ${ }^{32}$. An increased incidence of malignancies was recently suggested in our cohort of patients with SpA treated with anti-tumor necrosis factor (TNF) medications ${ }^{33}$. This suggests that the risk factors and comorbidities associated with psoriatic disease may be influenced by distinct factors including disease severity, treatment, and treatment response, and may differ for patients with only PsO and those with PsA.

Nevertheless, datasets about comorbidities in patients with PsA remain scarce and most available studies did not fully assess the potential influence of essential covariates such as age, sex, type of medications, disease duration, severity, education status, and work status that could have an effect on the development of these comorbidities. In addition, such data are rarely compared between related diseases within similar populations. We therefore documented and analyzed comorbidities in a cohort of patients with PsA from a single tertiary referral center and compared these incidences with those found in patients with other types of SpA in the same referral and management setting.

\section{MATERIALS AND METHODS}

Study population. Study participants were taken from the Leuven Spondyloarthritis Registry (SPAR), a prospective cohort study performed at the Division of Rheumatology of University Hospitals Leuven. This registry contains data on all patients with SpA including patients with PsA (from yrs 2000-2012) in clinical followup and able and willing to give informed consent. Patients enrolled in the database were diagnosed clinically as having SpA and were further subclassified into AS, PsA, IBD-associated arthritis, reactive arthritis, late-onset juvenile chronic arthritis, undifferentiated SpA, SAPHO (synovitis, acne, pustulosis, hyperostosis, and osteitis) syndrome, and idiopathic acute anterior uveitis. For reference, the European Spondylarthropathy Study Group SpA criteria ${ }^{34}$, the modified New York Criteria for $\mathrm{AS}^{35}$, and the CASPAR (ClASsification for Psoriatic ARthritis) criteria $^{36}$ for PsA were used. All patients with SpA presenting to the clinic who gave informed consent were included in our study, irrespective of their disease duration and severity. The patients who were not receiving TNF inhibition were followed up on a yearly basis, while the patients treated with TNF inhibitors were followed up every 2 months for the first year of the therapy and then every 3 months from the second year onward. Upon each visit to the outpatient clinic, detailed patient history and clinical and laboratory data were recorded. The database further contains demographic, drug treatment, and laboratory and radiological data. Ethical approval for the data collection was obtained from the Ethical Committee for Clinical Research at University Hospitals Leuven.

Comorbidity data collection. Comorbidities were recorded at baseline and prospectively by detailed patient history/medical records, clinical examination, medication history (e.g., use of lipid-lowering drugs or antihypertensives, etc.), and standardized laboratory tests. Comorbidities recorded in the patients and registered in the database include HTN, diabetes mellitus (DM) types I and II, CVD, arrhythmias, valve defects, depression, hyperlipidemia, hyperuricemia, gout, malignancy, stroke, chronic obstructive pulmonary disease, and multiple sclerosis. The CV comorbidity group included HTN, coronary artery disease (CAD), arrhythmias, valve defects, and other CVD whereas the metabolic comorbidity group included diabetes Types I and II, hyperlipidemia, hyperuricemia, and gout. The date and year of diagnosis for a comorbidity were also registered in the database. American Heart Association/National Heart, Lung, and Blood Institute metabolic syndrome criteria summarized below were used to further label the patients as metabolic syndrome-positive or -negative. Presence of 3 out of 5 risk factors constituted a diagnosis of metabolic syndrome ${ }^{37}$.

- $\quad$ Blood pressure $\geq 130 / 85 \mathrm{mmHg}$

- Fasting blood sugar $\geq 100 \mathrm{mg} / \mathrm{dl}$

- Large waist circumference: men 40 inches $(101.6 \mathrm{~cm})$ or more, and women 35 inches $(88.9 \mathrm{~cm})$ or more

- $\quad$ Low high-density lipoprotein cholesterol: men under $40 \mathrm{mg} / \mathrm{dl}$, and women under $50 \mathrm{mg} / \mathrm{dl}$

- Triglycerides $\geq 150 \mathrm{mg} / \mathrm{dl}$

We did not have the absolute fasting blood sugar values for the patients, so we used the established diagnosis of type II DM (from the patients' history and medical records) as a surrogate marker for this risk factor.

Data analysis. The data were analyzed after the database lock in December 2012. The basic demographic data (age, sex, disease duration, education, and work status) were analyzed using standard descriptive statistical methods, and patients were grouped into PsA and non-PsA SpA depending on their diagnosis. The data updated and recorded on the last visit were used for the analysis in all patients. Each group was separately analyzed on the basis of sex, age, education, work status, treatment, and type and number of comorbidities, and later compared with each other. Mean Psoriasis Area Severity Index (PASI) score was also calculated for patients with PsA to assess their current PsO status. Included patients were receiving treatment for their joint disease, skin disease, and coexisting comorbidities. Any difference in the prevalence of individual comorbidities based on their diagnosis, work status, disease duration, and education status was analyzed. Prevalence of each comorbidity was calculated in PsA and non-PsA SpA

Personal non-commercial use only. The Journal of Rheumatology Copyright (C) 2016. All rights reserved. 
groups, and any influence of the type of medication on these comorbidities was assessed. The data were first statistically analyzed using the chi-square test (Fisher's exact test where applicable) and Student t test at 0.05 level of significance and $\mathrm{p}$ values noted. The comorbidity groups with fewer than 5 individuals in any of the patient groups were excluded from further analysis. The 2 groups were then corrected for age, sex, disease duration, and type of medications, and analyzed using logistic regression model to rule out any influence of these confounding factors on the results. The cutoff set for the inclusion in the regression model was $\mathrm{p} \leq 0.1$, so only the comorbidities that showed a $\mathrm{p}$ value of $\leq 0.1$ in the initial analysis were included in the logistic regression model for further analysis. Bonferroni correction was applied to address the issue of multiple testing in regression analysis. OR and 95\% CI were calculated and the $\mathrm{p}$ values noted. Influence of sex on the prevalence of these individual comorbidities in both the groups was also assessed in this logistic regression model. All the comorbidity data were analyzed using logistic regression analysis at corrected significance level 0.007. Statistical analysis was performed using SPSS version 20 .

\section{RESULTS}

Characteristics of the patient groups. At the time of database lock for the analyses reported here, the SPAR database included 518 patients (1941.5 registered followup yrs, mean prospective followup $3.58 \mathrm{yrs} \pm 2.66 \mathrm{SD}$ per patient). Two hundred sixty-two patients were diagnosed with PsA and 256 patients with other forms of SpA (non-PsA SpA; 198 AS, 5 reactive arthritis, $8 \mathrm{IBD}-\mathrm{SpA}, 38$ undifferentiated $\mathrm{SpA}, 4$ late onset juvenile chronic arthritis, 2 SAPHO syndrome, and 1 idiopathic acute anterior uveitis). Malignancies recorded in the patients with PsA included 4 prostate malignancies, 7 breast malignancies, 1 non-Hodgkin lymphoma, 1 rectosigmoid carcinoma, 1 cervical carcinoma, 3 bladder malignancies, 1 oropharyngeal carcinoma, 1 undifferentiated ductal cell carcinoma with microcalcification, 1 follicular carcinoma of thyroid, and 1 Merkel tumor. The malignancies recorded in the non-PsA SpA group included 1 malignant melanoma, 1 basal cell carcinoma of scalp, 1 malignant mesothelioma, 1 large cell lung carcinoma, 1 cystadenoma, 1 chronic myeloid leukemia, and 1 malignant ampulloma. On one hand, patients with PsA were significantly older than patients with non-PsA SpA (mean 58.8 vs 44.9 yrs), while on the other hand, patients with non-PsA SpA had significantly longer disease duration when compared with patients with PsA $(\mathrm{p}<$ 0.001 ; Table 1). Other demographic characteristics of the 2 groups are also shown in Table 1. Sex distribution was not different between the 2 disease groups. Whereas the work status among the 2 groups showed a significant difference, with more working persons in the non-PsA SpA group $(\mathrm{p}=$ 0.01 ), no difference was observed in overall education status of the 2 groups except for a difference in the number of patients with primary education only. A more detailed analysis of the work status in the 2 groups revealed an older population in the PsA group, with $40.76 \%$ retired persons (Table 1). The patients with PsA had a mean PASI score of $1.77 \pm 5.05 \mathrm{SD}$.

Influence of diagnosis on comorbidities. Taking into account all patients, $53.66 \%$ of those included in the database had comorbidities. The PsA group had significantly more comor-
Table 1. Demographic and general characteristics of the PsA and non-PsA SpA groups. Values are $\mathrm{n}(\%)$ unless otherwise specified.

\begin{tabular}{lccc}
\hline Characteristics & PsA & Non-PsA SpA & $\mathrm{p}$ \\
\hline $\begin{array}{l}\text { No. patients } \\
\text { Age, yrs }\end{array}$ & 262 & 256 & \\
$\quad$ Range & $21-79$ & $19-77$ & \\
Mean \pm SD & $58.8 \pm 12.03$ & $44.9 \pm 12.89$ & $<0.001^{*}$ \\
$\quad$ Median age & 55 & 44 & \\
Male & $158(60.30)$ & $167(65.23)$ & 0.28 \\
Disease duration, yrs, & & & \\
$\quad$ mean \pm SD & $7.12 \pm 7.65$ & $14.10 \pm 11.43$ & $<0.001^{*}$ \\
Education & & & \\
$\quad$ Primary & $32(12.21)$ & $10(3.90)$ & $0.001^{*}$ \\
$\quad$ Secondary & $118(45.03)$ & $131(51.17)$ & 0.16 \\
College/university & $80(30.53)$ & $78(30.46)$ & 0.98 \\
$\quad$ Not recorded & $32(12.21)$ & $37(14.45)$ & 0.45 \\
Work status & & & \\
$\quad$ Working & $108(41.22)$ & $138(53.90)$ & $0.01^{*}$ \\
$\quad$ Not working & $130(49.61)$ & $106(41.40)$ & $0.01^{*}$ \\
$\quad$ On pension & $53(40.76)$ & $20(18.86)$ & \\
$\quad$ Sickness & $64(49.23)$ & $73(68.86)$ & \\
$\quad$ Others & $13(10.00)$ & $13(12.26)$ & $0.04^{*}$ \\
Other categories & $24(9.16)$ & $12(4.68)$ & \\
\hline
\end{tabular}

* Statistically significant. PsA: psoriatic arthritis; non-PsA SpA: non-psoriatic spondyloarthritis.

bidities compared with the non-PsA SpA group ( $\mathrm{p}<0.001$; Table 2). The presence of more comorbidities in the PsA group compared with the non-PsA SpA group was also confirmed by the logistic regression analysis of the data with correction for confounding factors (age, sex, disease duration, type of medication; OR 1.70, 95\% CI 1.13-2.56, $\mathrm{p}=0.001$ ). In addition, $29.77 \%$ of all the patients in the PsA group were found to have multiple comorbidities, either from the same or from different comorbidity groups compared with $16.40 \%$ of the non-PsA SpA group ( $\mathrm{p}<0.001$; Table 2).

Types of comorbidities in patients with PsA and non-PsA SpA. The distribution of the different comorbidities within the

Table 2. Distribution of comorbidities in the PsA and non-PsA SpA groups Values are n (\%) unless otherwise specified.

\begin{tabular}{lccc}
\hline Variables & PsA & Non-PsA SpA & p \\
\hline No. patients with & & & \\
$\quad$ comorbidities & $164 / 262(62.59)$ & $114 / 256(44.53)$ & $<0.001^{*}$ \\
Males with comorbidities & $97 / 164(59.14)$ & $72 / 114(63.15)$ & 0.50 \\
Multiple comorbidities & $78 / 262(29.77)$ & $42 / 256(16.40)$ & $<0.001^{*}$ \\
At least 1 CV comorbidity & $86 / 262(32.82)$ & $50 / 256(19.53)$ & $<0.001^{*}$ \\
More than 1 CV comorbidity & $25 / 262(9.54)$ & $12 / 256(4.68)$ & $0.03^{*}$ \\
At least 1 metabolic & & & \\
$\quad$ comorbidity & $65 / 262(24.80)$ & $28 / 256(10.93)$ & $<0.001^{*}$ \\
More than 1 metabolic & & & 0.17 \\
$\quad$ comorbidity & $21 / 262(8.01)$ & $13 / 256(5.07)$ & 0.175 \\
Total no. comorbidities & 298 & 175 & \\
\hline
\end{tabular}

* Statistically significant. PsA: psoriatic arthritis; non-PsA SpA: non-psoriatic spondyloarthritis; CV: cardiovascular. 
patient groups is shown in Table 3. Among all the comorbidities, the largest group were CVD in both patients with PsA and non-PsA SpA. The CVD burden was significantly higher in the PsA group compared with the non-PsA SpA group ( $\mathrm{p}<0.001)$. Similarly, we also found an increase in the prevalence of overall metabolic diseases in the PsA group ( $p$ $<0.001$ ). Among all the individual CV and metabolic comorbidities, HTN, CAD, and hyperlipidemia showed a marked difference between the 2 groups $(\mathrm{p}<0.001, \mathrm{p}=0.02$, and $\mathrm{p}$ $<0.001$, respectively; Table 3 ).

Significantly more patients in the PsA group $(9.92 \%)$ met the criteria for metabolic syndrome ${ }^{36}$ compared with those in the non-PsA SpA group (4.68\%, p = 0.03; Table 3). The difference between the 2 groups remained significant when using a logistic regression model with correction for confounding factors (age, sex, disease duration, and medication; OR 1.58, 95\% CI 1.32-1.88, p < 0.001). This regression model not only showed an increased prevalence of HTN, CAD, and hyperlipidemia in the patients with PsA (OR $1.81,1.39$, and 1.60 , respectively, $\mathrm{p}<0.001$ ), but also showed a significant difference in the prevalence of diabetes after controlling for all the confounding factors (OR 1.35, 95\% CI $1.17-1.56, \mathrm{p}<0.001$; Table 4). Different components of the metabolic syndrome (i.e., waist circumference and triglyceride level) were also significantly different between the 2 groups. Mean values of the different components of metabolic syndrome are shown in Table 5. Similarly, an increased incidence of malignancy was found in the PsA group compared with non-PsA SpA using chi-square statistics $(\mathrm{p}=0.02)$, which also remained significant using a logistic regression model (OR $1.27,95 \%$ CI 1.10-1.46, $\mathrm{p}=0.001$; Table 4).

Table 3. Prevalence of comorbidities in patients with PsA and non-PsA SpA. Values are $\mathrm{n}(\%)$ unless otherwise specified.

\begin{tabular}{lccc}
\hline Type of Comorbidity & PsA & Non-PsA SpA & $\mathrm{p}$ \\
\hline CVD & $133(50.76)$ & $84(32.81)$ & $<0.001^{*}$ \\
Hypertension & $86(32.82)$ & $50(19.53)$ & $<0.001^{*}$ \\
Arrhythmias & $20(7.63)$ & $18(7.03)$ & 0.92 \\
Coronary artery disease & $18(6.87)$ & $6(2.34)$ & $0.02^{*}$ \\
Other CVD & $4(1.52)$ & $4(1.56)$ & 1.00 \\
Valve defects & $5(1.90)$ & $6(2.34)$ & 0.96 \\
Metabolic diseases & $104(39.69)$ & $51(19.92)$ & $<0.001^{*}$ \\
Gout & $3(1.14)$ & $6(2.34)$ & 0.33 \\
Hyperuricemia & $19(7.25)$ & $9(3.51)$ & 0.09 \\
Diabetes & $17(6.48)$ & $8(3.12)$ & 0.10 \\
Hyperlipidemia & $65(24.80)$ & $28(10.93)$ & $<0.001^{*}$ \\
Malignancy & $20(7.63)$ & $7(2.73)$ & $0.02^{*}$ \\
Others & $35(13.35)$ & $32(12.50)$ & 0.77 \\
Depression & $26(9.92)$ & $27(10.54)$ & 0.81 \\
Stroke & $6(2.29)$ & $1(0.39)$ & 0.12 \\
COPD & $3(1.14)$ & $4(1.56)$ & 0.72 \\
Metabolic syndrome & $26(9.92)$ & $12(4.68)$ & $0.03^{*}$ \\
\hline
\end{tabular}

* Statistically significant. PsA: psoriatic arthritis; non-PsA SpA: non-psoriatic spondyloarthritis; CVD: cardiovascular disease; COPD: chronic obstructive pulmonary disease.
Table 4. Logistic regression model for comorbidities and psoriatic arthritis after controlling for age, sex, disease duration, and medication.

\begin{tabular}{lcc}
\hline Variable & OR $(95 \% \mathrm{CI})$ & $\mathrm{p}$ \\
\hline Diabetes & $1.35(1.17-1.56)$ & $<0.001^{*}$ \\
Hyperlipidemia & $1.60(1.46-1.75)$ & $<0.001^{*}$ \\
Hypertension & $1.81(1.66-1.97)$ & $<0.001^{*}$ \\
Coronary artery disease & $1.39(1.19-1.64)$ & $<0.001^{*}$ \\
Hyperuricemia & $1.61(1.39-1.86)$ & $<0.001^{*}$ \\
Malignancy & $1.27(1.10-1.46)$ & $0.001^{*}$ \\
Metabolic syndrome & $1.58(1.32-1.88)$ & $<0.001^{*}$ \\
\hline
\end{tabular}

* Statistically significant.

Table 5. Individual values for metabolic syndrome components in the PsA and non-PsA SpA groups. Values are mean \pm SD unless otherwise specified.

\begin{tabular}{llll}
\hline Variables & PsA & Non-PsA SpA & p \\
\hline
\end{tabular}

Mean waist circumference,

$\begin{array}{llll}\mathrm{cm} & 102.46 \pm 14.15 & 98.29 \pm 16.75 & 0.02 *\end{array}$

Mean blood pressure, $\mathrm{mmHg}$

$\begin{array}{llll}\text { Systolic } & 142.04 \pm 20.26 & 139 \pm 17.84 & 0.19\end{array}$

$\begin{array}{lll}\text { Diastolic } \quad 81.98 \pm 10.57 & 81.66 \pm 11.48 \quad 0.80\end{array}$

Mean HDL cholesterol, $\mathrm{mg} / \mathrm{dl}$

Mean triglyceride level, $\mathrm{mg} / \mathrm{dl}$

Mean fasting blood glucose

$$
54.93 \pm 20.38 \quad 56.75 \pm 18.39 \quad 0.28
$$

$163.07 \pm 103.34 \quad 133.47 \pm 84.90<0.001^{*}$ NA NA

* Statistically significant. PsA: psoriatic arthritis; non-PsA SpA: non-psoriatic spondyloarthritis, HDL: high-density lipoprotein; NA: not available.

Influence of therapy. We further analyzed the groups to see whether there were differences on the basis of treatment [use of TNF blockers or disease-modifying antirheumatic drugs (DMARD)] in patients among the comorbidity and noncomorbidity groups of PsA and non-PsA SpA. Among all the patients with comorbidities, $51.38 \%$ of patients were receiving TNF blockers whereas $48.61 \%$ were receiving DMARD. TNF blockers were administered equally in patients with and without comorbidities in both the PsA and non-PsA SpA groups ( $p>0.05$; Table 6). Therefore, we did not find any difference in the prevalence of comorbidities among the 2 groups based on their treatment.

Influence of sex on the distribution of comorbidities. A higher probability of diabetes Type II, gout, hyperuricemia, stroke, and CAD was found in men, while malignancy, depression, and HTN were found to be more common in women ( $p<$ 0.001 ) in both the PsA and non-PsA SpA groups. Work status and level of education in the 2 groups were not related to the presence or absence of comorbidities.

\section{DISCUSSION}

To our knowledge, ours is the first cross-sectional study about PsA and its association with comorbidities in the Belgian population compared with a non-PsA SpA population.

Personal non-commercial use only. The Journal of Rheumatology Copyright @ 2016 . All rights reserved. 
Table 6. Distribution of medication in comorbidity and non-comorbidity groups of PsA and non-PsA SpA. Values are n (\%) unless otherwise specified.

\begin{tabular}{lccc}
\hline Patients & TNF Blockers & DMARD & $\mathrm{p}$ \\
\hline PSA & & & \\
Comorbidity-positive & $57(24.78)$ & $87(37.82)$ & \\
Comorbidity-negative & $38(16.52)$ & $48(20.86)$ & 0.49 \\
Non-PsA SpA & & & \\
Comorbidity-positive & $54(35.29)$ & $18(11.76)$ & \\
Comorbidity-negative & $57(37.25)$ & $24(15.68)$ & 0.52 \\
\hline
\end{tabular}

PsA: psoriatic arthritis; non-PsA SpA: non-psoriatic spondyloarthritis; TNF: tumor necrosis factor; DMARD: disease-modifying antirheumatic drugs.

Although earlier work in $\mathrm{PsO}$ and PsA cohorts identified the importance of such comorbidity, our data provide novel information on the burden of psoriatic disease compared with patients having a closely related chronic skeletal disorder. The comorbidity and other patient data have been collected in the same manner under similar circumstances in a tertiary academic center and local community hospital to reduce the possibility of bias and were supported by clinical examinations and investigations.

The results of our study identify a high prevalence of $\mathrm{CV}$ comorbidities, in particular HTN and CAD, among the patients with PsA compared with non-PsA SpA. Similarly, an increased prevalence of metabolic diseases was also seen, with hyperlipidemia being the most prevalent. These results confirmed the previous observations from various parts of the world showing an increased prevalence of $\mathrm{CV}$ and metabolic comorbidities in PsA ${ }^{15,21,24,38}$. Our observations on malignancies appear to conflict with most of the earlier data ${ }^{31,32}$. Importantly, the increased prevalence of malignancy in the PsA group (12.19\%) was documented compared with the non-PsA SpA group (6.14\%). These malignancies did not only include skin malignancies, but also breast, prostate, bladder, lung, and gastrointestinal cancer. For now, we can only hypothesize about the reasons for this difference. Patients with psoriatic disease usually have an increased risk for skin cancer that is linked to increased sun exposure, which is often beneficial for their skin symptoms, or to UV light-based therapies. The increased frequency of other cancers could be influenced by genetic or lifestyle risk factors, including obesity, smoking, and alcohol use. The increased incidence of prostate and breast cancer in the PsA group is of particular interest. Our data could indicate the existence of shared risk factors between these cancers and PsA. Nevertheless, the relatively small sample in this exploratory study carries the intrinsic risk of attaching too much importance to this type of data. Therefore, we prefer not to further discuss the occurrence of breast and prostate cancers in our study, to avoid speculation that cannot be supported by our current dataset. Our data could indicate the existence of shared risk factors between these cancers and
PsA. At present we can only state a possible positive association between those diseases, indicating that this observation needs to be studied in further detail.

We also tried to see whether the difference between the 2 disease groups is influenced by the age, sex, duration of disease, type of medications (anti-TNF or DMARD), education, or work status. There was no difference found based on these factors among the 2 groups and neither was there any influence of these factors on the previous results. Supporting many studies in the literature, we also found a difference in the prevalence of diabetes Type II among the 2 groups compared in this setting $38,39,40$. An increased prevalence of DM type II was seen in a female population of the patients with PsA compared with controls in a population-based, cross-sectional study in Israel, whereas in our study population DM type II was found to be more prevalent in men than women after controlling for confounding factors such as age, medication, and disease duration ${ }^{39}$. Differences in patient groups and limitations of the sample size may explain some of these observations.

In our study, we also found more patients $(47.56 \%)$ in the PsA group with multiple comorbidities compared with the non-PsA SpA group, a finding that has not been reported in previous studies. This finding is of interest and further studies may be required to confirm it. The trend for having metabolic syndrome was also higher in the PsA group, which has been found in many previous studies $15,21,22$. The study by Haroon, et al showed a much higher prevalence of metabolic syndrome in their patients with PsA compared with our study (44\% vs $9.92 \%$, respectively) ${ }^{22}$. The 2 populations and the data available are not directly comparable and there can be several possible explanations for these varying results, including differences in the genetic background, socioeconomic conditions, and healthcare system between the 2 populations. This increase in the prevalence of metabolic syndrome likely confers a higher risk of developing CVD in these patients and may be one of the reasons for a higher prevalence of the $\mathrm{CV}$ comorbidities in the PsA group ${ }^{41}$.

There can be many explanations for the increase in comorbidity burden in patients with PsA. Obesity, diabetes, and $\mathrm{CVD}$ are the phenotypic expression of disturbances in the metabolic pathways. The chronic inflammatory process in PsA and PsO may underlie these metabolic changes and can be a possible pathogenic factor for these comorbidities, although it is unclear whether the metabolic disturbances are similar in PsO, PsA, and non-PsA SpA. There is growing evidence that these metabolic alterations in PsA are involved in raising the incidence of HTN, hyperlipidemia, and type II diabetes in these patients when compared with patients with $\mathrm{PsO}$, leading to an increased early mortality ${ }^{15,37,39}$. So targeting this chronic inflammation by TNF- $\alpha$ blockade or methotrexate not only reduces the incidence of $\mathrm{CV}$ events in $\mathrm{PsO}$ and PsA, but also lessens work disability and improves quality of life in these patients ${ }^{17,37,42,43,44}$.

Personal non-commercial use only. The Journal of Rheumatology Copyright $\odot$ 2016. All rights reserved. 
Another possible explanation for the increased comorbidities in patients with PsA can be a genetic pathway shared between PsA and these comorbidities. A number of genes and loci common for 4 autoimmune diseases (celiac disease, type 1 diabetes, Grave disease, and rheumatoid arthritis) are also found in PsO and PsA on chromosome 4q27, harboring the interleukin (IL)-2 and $I L-21$ genes as well as COG6. The latter is involved in intracellular transport and glycoprotein modification of ADAM proteases ${ }^{45,46}$. Adam33 has been suggested as a PsO-susceptibility gene ${ }^{46,47}$. CDKAL1, a gene associated with type 2 diabetes, also shows a strong association in $\mathrm{PsO}$, but the function of this gene is unknown ${ }^{48,49}$. Further research to study these metabolic and genetic pathways may be necessary to know in detail the underlying causes of this association of $\mathrm{CV}$ and metabolic comorbidities, as well as malignancy with PsA.

There is a significant increase in CV and metabolic comorbidities, including malignancy, in patients with PsA compared with non-PsA SpA, irrespective of demographic factors, disease duration, and type of treatment. Conventional confounders such as age, sex, disease duration, and therapy could not explain the difference. The cause for this increase is not known, but might be specifically disease-related and further research is necessary to understand the epidemiological and molecular causes.

\section{REFERENCES}

1. Scarpa R, Ayala F, Caporaso N, Olivieri I. Psoriasis, psoriatic arthritis, or psoriatic disease? J Rheumatol 2006;33:210-2.

2. Nestle FO, Kaplan DH, Barker J. Psoriasis. N Engl J Med 2009;361:496-509.

3. Haroon M, Fitzgerald O. Pathogenetic overview of psoriatic disease. J Rheumatol Suppl. 2012 Jul;89:7-10.

4. Gladman DD, Antoni C, Mease P, Clegg DO, Nash P. Psoriatic arthritis: epidemiology, clinical features, course, and outcome. Ann Rheum Dis 2005;64 Suppl 2:ii14-7.

5. Nash P, Mease PJ, Braun J, van der Heijde D. Seronegative spondyloarthropathies: to lump or split? Ann Rheum Dis 2005;64 Suppl 2:ii9-13.

6. Dougados M, Baeten D. Spondyloarthritis. Lancet 2011; 377:2127-37.

7. Langley RG, Krueger GG, Griffiths CE. Psoriasis: epidemiology, clinical features, and quality of life. Ann Rheum Dis 2005;64 Suppl 2:ii18-23.

8. Scarpa R. New insights into the concept of psoriatic disease. J Rheumatol Suppl. 2012 Jul;89:4-6.

9. Boehncke WH, Boehncke S, Schön MP. Managing comorbid disease in patients with psoriasis. BMJ 2010;340:b5666.

10. Daudén E, Castañeda S, Suárez C, García-Campayo J, Blasco AJ, Aguilar MD, et al; Working Group on Comorbidity in Psoriasis. Clinical practice guideline for an integrated approach to comorbidity in patients with psoriasis. J Eur Acad Dermatol Venereol 2013;27:1387-404.

11. Husni ME, Mease PJ. Managing comorbid disease in patients with psoriatic arthritis. Curr Rheumatol Rep 2010;12:281-7.

12. Abuabara K, Azfar RS, Shin DB, Neimann AL, Troxel AB, Gelfand JM. Cause-specific mortality in patients with severe psoriasis: a population-based cohort study in the U.K. Br J Dermatol 2010;163:586-92.
13. Arumugam R, McHugh NJ. Mortality and causes of death in psoriatic arthritis. J Rheumatol Suppl. 2012 Jul;89:32-5.

14. Buckley C, Cavill C, Taylor G, Kay H, Waldron N, Korendowych E, et al. Mortality in psoriatic arthritis - a single-center study from the UK. J Rheumatol 2010;37:2141-4.

15. Gladman DD, Ang M, Su L, Tom BD, Schentag CT, Farewell VT. Cardiovascular morbidity in psoriatic arthritis. Ann Rheum Dis 2009;68:1131-5.

16. Kimki O, Caspi D, Bornstein NM, Maharshak N, Gur A, Arbel Y, et al. Prevalence and risk factors of atherosclerosis in patients with psoriatic arthritis. Semin Arthritis Rheum 2007;36:203-9.

17. Tam LS, Tomlinson B, Chu TT, Li M, Leung YY, Kwok LW, et al. Cardiovascular risk profile of patients with psoriatic arthritis compared to controls - the role of inflammation. Rheumatology 2008;47:718-23.

18. Han C, Robinson DW Jr, Hackett MV, Paramore LC, Fraeman KH, Bala MV. Cardiovascular disease and risk factors in patients with rheumatoid arthritis, psoriatic arthritis, and ankylosing spondylitis. J Rheumatol 2006;33:2167-72.

19. Armstrong AW, Harskamp CT, Armstrong EJ. The association between psoriasis and hypertension: a systematic review and meta-analysis of observational studies. J Hypertens 2013; 31:433-42.

20. Gelfand JM, Yeung H. Metabolic syndrome in patients with psoriatic disease. J Rheumatol Suppl. 2012 Jul;89:24-8.

21. Armstrong AW, Schupp C, Bebo B. Psoriasis comorbidities: results from the National Psoriasis Foundation surveys 2003 to 2011. Dermatology 2012;225:121-6.

22. Haroon M, Gallagher P, Heffernan E, FitzGerald O. High prevalence of metabolic syndrome and of insulin resistance in psoriatic arthritis is associated with the severity of underlying disease. J Rheumatol 2014;41:1357-65.

23. Cohen AD, Dreiher J, Shapiro Y, Vidavsky L, Vardy DA, Davidovici $\mathrm{B}$, et al. Psoriasis and diabetes: a population-based cross-sectional study. J Eur Acad Dermatol Venereol 2008;22:585-9.

24. Vena GA, Altomare G, Ayala F, Berardesca E, Calzavara-Pinton P, Chimenti S, et al. Incidence of psoriasis and association with comorbidities in Italy: a 5-year observational study from a national primary care database. Eur J Dermatol 2010;20:593-8.

25. Love TJ, Zhu Y, Zhang Y, Wall-Burns L, Ogdie A, Gelfand JM, et al. Obesity and the risk of psoriatic arthritis: a population-based study. Ann Rheum Dis 2012;71:1273-7.

26. Grundy SM, Brewer HB Jr, Cleeman JI, Smith SC Jr, Lenfant C; American Heart Association; National Heart, Lung, and Blood Institute. Definition of metabolic syndrome: Report of the National Heart, Lung, and Blood Institute/American Heart Association conference on scientific issues related to definition. Circulation 2004;109:433-8.

27. Khraishi M, Aslanov R, Rampakakis E, Pollock C, Sampalis JS. Prevalence of cardiovascular risk factors in patients with psoriatic arthritis. Clin Rheumatol 2014;33:1495-500.

28. Boehncke WH, Boehncke S, Tobin AM, Kirby B. The 'psoriatic march': a concept of how severe psoriasis may drive cardiovascular comorbidity. Exp Dermatol 2011;20:303-7.

29. Jamnitski A, Symmons D, Peters MJ, Sattar N, McInnes I, Nurmohamed MT. Cardiovascular comorbidities in patients with psoriatic arthritis: a systematic review. Ann Rheum Dis 2013;72:211-6.

30. Olsen JH, Møller H, Frentz G. Malignant tumors in patients with psoriasis. J Am Acad Dermatol 1992;27:716-22.

31. Ishioka S, Maeda A, Jougasaki Y, Hiyama K, Yamakido M. Psoriatic arthritis complicating lung cancer. Intern Med 2000;39:185-7.

32. Rohekar S, Tom BD, Hassa A, Schentag CT, Farewell VT, Gladman DD. Prevalence of malignancy in psoriatic arthritis. Arthritis Rheum 2008;58:82-7.

Personal non-commercial use only. The Journal of Rheumatology Copyright $\subset$ 2016. All rights reserved. 
33. Westhovens I, Lories RJ, Westhovens R, Verschueren P, de Vlam K. Anti-TNF therapy and malignancy in spondyloarthritis in the Leuven spondyloarthritis biologics cohort (BIOSPAR). Clin Exp Rheumatol 2014;32:71-6.

34. Dougados M, van der Linden S, Juhlin R, Huitfeldt B, Amor B, Calin A, et al. The European Spondylarthropathy Study Group preliminary criteria for the classification of spondylarthropathy. Arthritis Rheum 1991;34:1218-27.

35. van der Linden S, Valkenburg HA, Cats A. Evaluation of diagnostic criteria for ankylosing spondylitis. A proposal for modification of the New York criteria. Arthritis Rheum 1984;27:361-8.

36. Taylor W, Gladman D, Helliwell P, Marchesoni A, Mease P, Mielants H; CASPAR Study Group. Classification criteria for psoriatic arthritis: development of new criteria from a large international study. Arthritis Rheum 2006;54:2665-73.

37. PubMed Health. Metabolic syndrome. [Internet. Accessed October 28, 2015.]. Available from: www.ncbi.nlm.nih.gov/pubmedhealth/ PMH0004546

38. Husted JA, Thavaneswaran A, Chandran V, Eder L, Rosen CF, Cook RJ, et al. Cardiovascular and other comorbidities in patients with psoriatic arthritis: a comparison with patients with psoriasis. Arthritis Care Res 2011;63:1729-35.

39. Dreiher J, Freud T, Cohen AD. Psoriatic arthritis and diabetes: a population-based cross-sectional study. Dermatol Res Pract 2013;2013:580404.

40. Dubreuil M, Rho YH, Man A, Zhu Y, Zhang Y, Love TJ, et al. Diabetes incidence in psoriatic arthritis, psoriasis and rheumatoid arthritis: a UK population-based cohort study. Rheumatology 2014;53:346-52.

41. Favarato MH, Mease P, Gonçalves CR, Gonçalves Saad C, Sampaio-Barros PD, Goldenstein-Schainberg C. Hypertension and diabetes significantly enhance the risk of cardiovascular disease in patients with psoriatic arthritis. Clin Exp Rheumatol 2014;32:182-7.
42. Roubille C, Richer V, Starnino T, McCourt C, McFarlane A, Fleming $\mathrm{P}$, et al. The effects of tumour necrosis factor inhibitors, methotrexate, non-steroidal anti-inflammatory drugs and corticosteroids on cardiovascular events in rheumatoid arthritis, psoriasis and psoriatic arthritis: a systematic review and meta-analysis. Ann Rheum Dis 2015;74:480-9.

43. Sattar N, Crompton P, Cherry L, Kane D, Lowe G, McInnes IB. Effects of tumor necrosis factor blockade on cardiovascular risk factors in psoriatic arthritis: a double-blind, placebo-controlled study. Arthritis Rheum 2007;56:831-9.

44. Kristensen LE, Englund M, Neovius M, Askling J, Jacobsson LT, Petersson IF. Long-term work disability in patients with psoriatic arthritis treated with anti-tumour necrosis factor: a population-based regional Swedish cohort study. Ann Rheum Dis 2013;72:1675-9.

45. Naranjo A, Sokka T, Descalzo MA, Calvo-Alén J, Hørslev-Petersen K, Luukkainen RK, et al; QUEST-RA Group. Cardiovascular disease in patients with rheumatoid arthritis: results from the QUEST-RA study. Arthritis Res Ther 2008;10:R30.

46. Liu Y, Helms C, Liao W, Zaba LC, Duan S, Gardner J, et al. A genome-wide association study of psoriasis and psoriatic arthritis identifies new disease loci. PLoS Genet 2008;4:e1000041.

47. Sharma N, Tripathi P, Awasthi S. Role of ADAM33 gene and associated single nucleotide polymorphisms in asthma. Allergy Rhinol 2011;2:e63-70.

48. Wolf N, Quaranta M, Prescott NJ, Allen M, Smith R, Burden AD, et al. Psoriasis is associated with pleiotropic susceptibility loci identified in type II diabetes and Crohn disease. J Med Genet 2008;45:114-6.

49. Haupt A, Guthoff M, Gallwitz B, Haring HU, Fritsche A. Variation in the CDKAL1 gene is associated with the titer of antibodies to GAD. Diabetes Care 2008;31:e66. 